\title{
Influence of Anvil Wear on Charpy Test Results - NIST Contribution to an International Study
}

\author{
Enrico Lucon \\ Raymond L. Santoyo
}

This publication is available free of charge from:

https://doi.org/10.6028/NIST.TN.2089

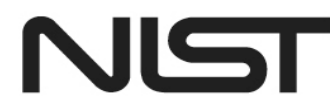

National Institute of Standards and Technology U.S. Department of Commerce 


\title{
Influence of Anvil Wear on Charpy Test Results - NIST Contribution to an International Study
}

\author{
Enrico Lucon \\ Raymond L. Santoyo \\ Applied Chemicals and Materials Division \\ Material Measurement Laboratory
}

This publication is available free of charge from:

https://doi.org/10.6028/NIST.TN.2089

March 2020

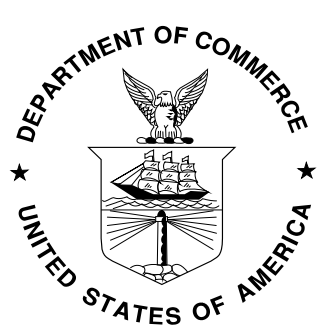

U.S. Department of Commerce Wilbur L. Ross, Jr., Secretary

National Institute of Standards and Technology 
Certain commercial entities, equipment, or materials may be identified in this document in order to describe an experimental procedure or concept adequately. Such identification is not intended to imply recommendation or endorsement by the National Institute of Standards and Technology, nor is it intended to imply that the entities, materials, or equipment are necessarily the best available for the purpose.

National Institute of Standards and Technology Technical Note 2089

Natl. Inst. Stand. Technol. Tech. Note 2089, 25 pages (March 2020) CODEN: NTNOEF

This publication is available free of charge from:

https://doi.org/10.6028/NIST.TN.2089 


\begin{abstract}
We investigated the influence of the state of wear of Charpy machine anvils on test results by performing impact tests on NIST specimens of three energy levels with a machine equipped with new anvils (compliant with both ASTM E23 and ISO 148-2) and worn anvils (anvil corner radii and distance outside ASTM tolerances, but within ISO tolerances).

The results obtained, statistically analyzed, unequivocally show that worn anvils tend to increase absorbed energy at all energy levels. On the other hand, data variability does not appear to be significantly affected by anvil wear.

This study represents NIST contribution to an international effort spearheaded by the Japan Iron and Steel Federation Standardization Center (Tokyo, Japan).
\end{abstract}

\title{
Key words
}

Absorbed energy, ASTM E23, Charpy, ISO 148, machine anvils, span, wear. 
Table of Contents

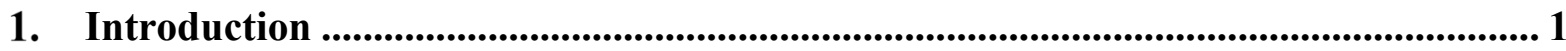

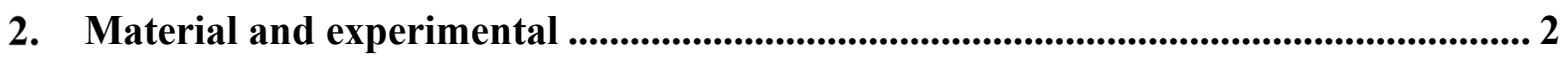

3. Selection of the worn anvils ................................................................................. 2

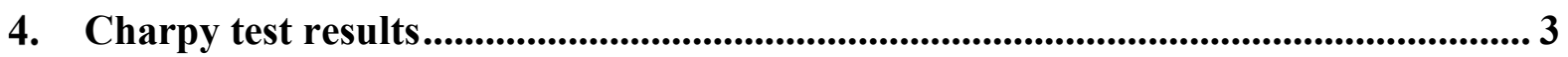

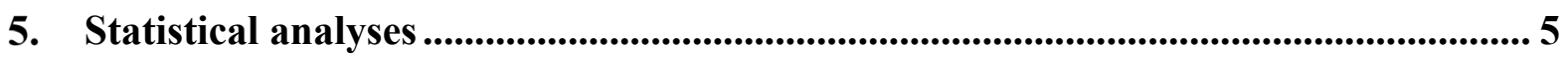

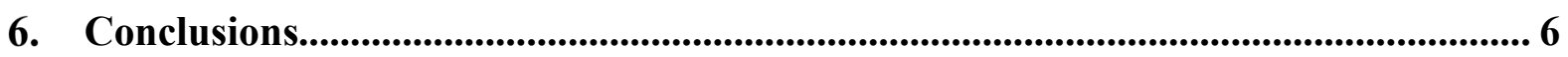

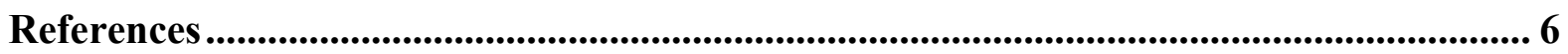

\section{List of Figures}

Figure 1 - Representation of a Charpy specimen being impacted during a test. "1" refers to the distance between the anvils (span), while " 2 " and " 3 " indicate anvil radius and angle, respectively [1].

Figure 2 - Measurement of worn anvil radius (from Data collection protocol, Annex 2).

\section{List of Tables}

Table 1 - Radius measurements on worn anvils.

Table 2 - Charpy tests results obtained with new anvils.

Table 3 - Charpy tests results obtained with worn anvils.

Table 4 - Summary of two-tailed $F$-tests on the equality of variances $(\alpha=0.05)$.

Table 5 - Summary of two-tailed $t$-tests on the equality of means $(\alpha=0.05)$.

\section{List of Annexes}

ANNEX 1 Presentation by A. Ishikawa, Japan Iron and Steel Federation (5/14/2019)

ANNEX 2 Data Collection Protocol

ANNEX 3 Pictures of anvil replicas with inscribed circles 


\section{Introduction}

Charpy impact testing is standardized in several national and international norms, the most widely used being ASTM E23-18 [1] and ISO 148-1 [2].

Test standards precisely define the dimensions and tolerances for test specimens and every part of the machine. This facilitates the comparison between results obtained by different laboratories.

While most of the specimen and machine dimensions are identical or at least very similar between ASTM and ISO, some tolerances are significantly different, with ASTM E23 typically more stringent than ISO 148. An example is the tolerance on the corner radius of the machine anvils ${ }^{1}$ (nominal value $=1.00 \mathrm{~mm}$ ), which ASTM E23 requires to be $\pm 0.05 \mathrm{~mm}$, while ISO 148-2 [3] prescribes ${ }_{-0.00}^{+0.50} \mathrm{~mm}$. Figure 1, taken from ASTM E23, shows the configuration of anvils (top) and supports ${ }^{2}$ (bottom) of a Charpy machine.

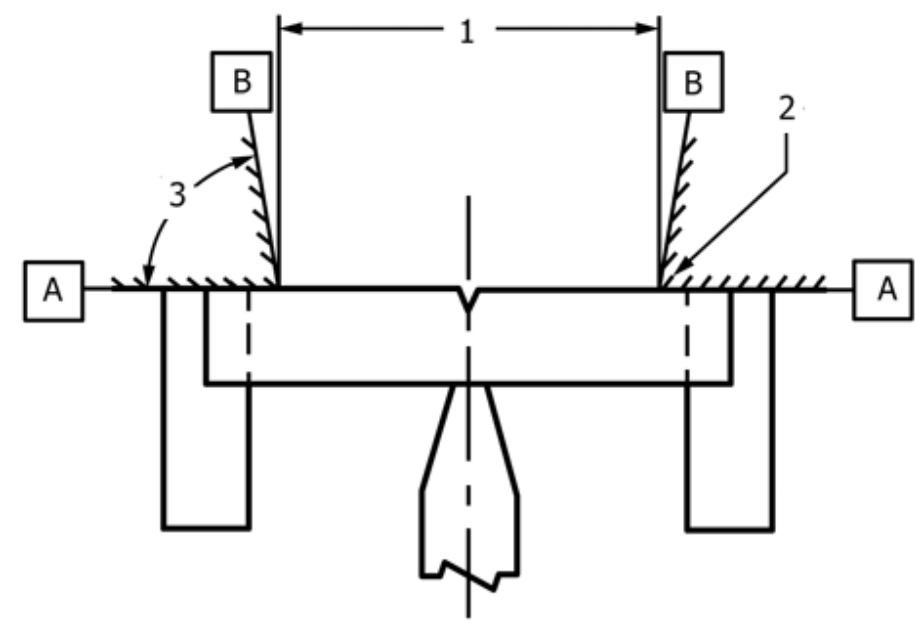

Figure 1 - Representation of a Charpy specimen being impacted during a test. Dimension "1" refers to the distance between the anvils (span), while " 2 " and " 3 " indicate anvil radius and angle, respectively [1].

Similar to any machine part in contact with the specimen during a test, anvils are subject to wear, which tends to increase the corner radii and eventually cause them to become out of tolerance. Other anvil features that are progressively modified by wear are surface roughness ("A" in Figure 1) and span ("1" in Figure 1). The nominal values and tolerances for these parameters in ASTM E23 and ISO 148-2 are:

- Surface roughness: Ra $\leq 0.1 \mu \mathrm{m}$ (ASTM E23); not specified in ISO 148-2.

- Span: $40.00 \mathrm{~mm} \pm 0.05 \mathrm{~mm}$ (ASTM E23); $40.00 \mathrm{~mm}_{-0.00}^{+0.50} \mathrm{~mm}$ (ISO 148-2).

During the meeting of ASTM E28.07 subcommittee (Impact Testing) that took place in Atlanta, GA, in November 2017, Mr. Atsushi Ishikawa from the Japan Iron and Steel Federation (Tokyo, Japan) presented a proposal aimed at harmonizing anvil tolerances between ASTM and ISO. Specifically, he suggested revising ASTM E23 to allow the same tolerances

\footnotetext{
${ }^{1}$ According to the ISO 148-1 Terms and Definitions section (3.1.1), the anvil is a "portion of the machine that serves to properly position the test piece for impact with respect to the striker and the test piece supports, and supports the test piece under the force of the strike."

${ }^{2}$ Supports are the parts of the machine on which the specimen rests.
} 
as in ISO 148-2 for anvil corner radius and span. A presentation by Mr. Ishikawa, summarizing his position on the topic, is included in Annex 1.

This ASTM E23 revision was balloted in 2018, but changes were rejected on account of the insufficient experimental data available to support a relaxation of the ASTM tolerances. Hence, Mr. Ishikawa decided to set up an international effort aimed at collecting experimental test data from Charpy tests performed with new and worn anvils. The Data Collection Protocol, written in collaboration with NIST in Boulder, is provided in Annex 2.

NIST volunteered to participate in this joint effort, by testing and statistically analyzing Charpy data from specimens corresponding to different energy levels. This report presents the results and the statistical analyses of the tests performed.

\section{Material and experimental}

Three types of NIST Charpy specimens were selected for this study:

- low-energy specimens (4340 steel, lot LL-157),

- high-energy specimens (4340 steel, lot HH-170), and

- $\quad$ super-high-energy specimens (9310 steel, lot SH-56).

Tests were performed at room temperature $\left(21^{\circ} \mathrm{C} \pm 1{ }^{\circ} \mathrm{C}\right)$ on a Charpy machine with a capacity (potential energy) of $953.6 \mathrm{~J}$ and an impact speed of $5.47 \mathrm{~m} / \mathrm{s}$. The machine was equipped with a non-instrumented striker with $8 \mathrm{~mm}$ radius of the striking edge.

For each anvil condition (new and worn), 60 Charpy tests were conducted (25 at lowand high-energy level, 10 at super-high-energy level).

\section{Selection of the worn anvils}

Four pairs of used (worn) anvils were available for the chosen machine. In order to select the best pair for investigating the "worn" condition, we obtained replicas (molds) of the used anvil profiles by means of a silicone-type material, generally used for dental impressions. Once dried and solidified, replicas were sectioned in two positions (P1, P2), both inside the contact area between anvil and specimen (worn area).

In accordance with Figure 2, taken from the Data Collection Protocol, radius measurements ( $r_{\mathrm{P} 1}$ and $r_{\mathrm{P} 2}$ for the two replica sections) were obtained by taking pictures of the replica sections and inscribing a circle on each picture, tangent to both sides of the anvil. The average of the radii of the inscribed circles for the two replica sections was taken as the radius for each worn anvil (Table 1).

Table 1 - Corner radius measurements on worn anvils.

\begin{tabular}{|c|c|c|c|}
\hline Anvil & $\begin{array}{c}r_{\mathrm{P} 1} \\
(\mathrm{~mm})\end{array}$ & $\begin{array}{c}r_{\mathrm{P} 2} \\
(\mathrm{~mm})\end{array}$ & $\begin{array}{c}\bar{r} \\
(\mathrm{~mm})\end{array}$ \\
\hline $\mathrm{A}$ & 1.28 & 1.17 & 1.14 \\
$\mathrm{~B}$ & 1.15 & 1.26 & 1.21 \\
\hline $\mathrm{C}$ & 1.52 & 1.56 & 1.54 \\
$\mathrm{D}$ & 1.32 & 1.68 & 1.50 \\
\hline $\mathrm{E}$ & 1.06 & 1.11 & 1.09 \\
$\mathrm{~F}$ & 1.17 & 1.21 & 1.19 \\
\hline $\mathrm{G}$ & 1.44 & 1.31 & 1.38 \\
$\mathrm{H}$ & 1.47 & 1.19 & 1.33 \\
\hline
\end{tabular}




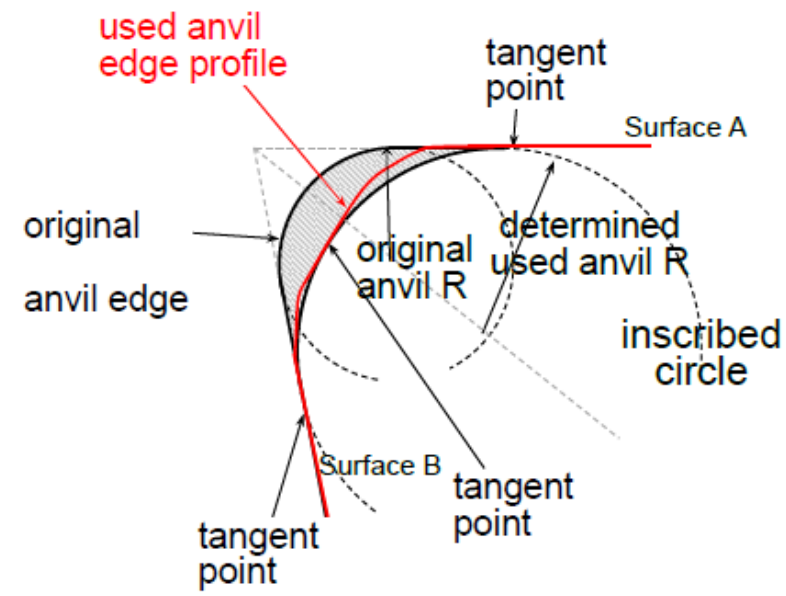

Figure 2 - Measurement of worn anvil radius (from Data collection protocol, Annex 2).

Annex 3 collects all the pictures taken from the replicas, showing also the inscribed circles and the corresponding corner radius $(r)$.

Based on the measurements performed, anvils $\mathrm{G}$ (average radius, $\bar{r}=1.38 \mathrm{~mm}$ ) and $\mathrm{H}$ $(\bar{r}=1.33 \mathrm{~mm})$ were selected for the tests in the worn condition. They represent a case that is clearly beyond the ASTM allowable limit $\left(r_{\max }=1.05 \mathrm{~mm}\right)$, but well within the ISO limit ( $r_{\max }$ $=1.50 \mathrm{~mm}$ ). Moreover, the difference between the measured radii and the two limits is large enough to provide some margin with respect to possible measurement uncertainties.

After worn anvils $\mathrm{G}$ and $\mathrm{H}$ were installed on the Charpy machine, we used a caliper to measure their distance (span), which was found to be equal to $40.10 \mathrm{~mm}$. This is invalid according to ASTM E23 ( $>40.05 \mathrm{~mm})$, but acceptable per ISO $148-2(\leq 40.20 \mathrm{~mm})$.

\section{Charpy test results}

The values of absorbed energy, $K V(\mathrm{~J})$, obtained with new and worn anvils, are provided in Table 2 and Table 3, respectively.

Table 2 - Charpy test results obtained with new anvils, including average values $(\overline{K V})$ and standard deviations.

\begin{tabular}{|c|c|c|c|c|c|}
\hline \multicolumn{2}{|c|}{ Low energy (LL-157) } & \multicolumn{2}{c|}{ High energy (HH-170) } & \multicolumn{2}{c|}{ Super-high energy (SH-56) } \\
Specimen ID & KV (J) & Specimen ID & KV (J) & Specimen ID & KV (J) \\
\hline 2056 & 30.30 & 586 & 95.84 & 1306 & 239.91 \\
1244 & 29.27 & 1258 & 100.55 & 1581 & 245.35 \\
55 & 26.98 & 519 & 108.00 & 1558 & 242.34 \\
1224 & 25.01 & 846 & 101.86 & 1065 & 233.43 \\
167 & 23.68 & 612 & 106.59 & 1251 & 244.09 \\
437 & 21.72 & 830 & 110.47 & 1266 & 259.19 \\
1119 & 18.92 & 1214 & 98.19 & 2056 & 241.17 \\
965 & 19.23 & 983 & 97.58 & 1963 & 234.49 \\
1726 & 21.49 & 432 & 102.82 & 1940 & 264.27 \\
2357 & 27.61 & 667 & 96.36 & 1699 & 235.84 \\
1939 & 30.46 & 1037 & 106.41 & & \\
2719 & 32.44 & 815 & 109.76 & & \\
2065 & 31.57 & 386 & 110.91 & & \\
\hline
\end{tabular}




\begin{tabular}{|c|c|c|c|c|c|}
\hline \multicolumn{2}{|c|}{ Low energy (LL-157) } & \multicolumn{2}{c|}{ High energy (HH-170) } & \multicolumn{2}{|c|}{ Super-high energy (SH-56) } \\
Specimen ID & KV (J) & Specimen ID & KV (J) & Specimen ID & KV (J) \\
\hline 1327 & 31.49 & 1223 & 111.44 & & \\
117 & 31.01 & 875 & 102.91 & \\
2514 & 31.17 & 870 & 98.97 & \\
1739 & 31.01 & 1246 & 97.93 & \\
1545 & 25.56 & 622 & 102.99 & & \\
139 & 26.11 & 927 & 92.20 & & \\
2729 & 23.68 & 228 & 111.79 & & \\
1271 & 20.63 & 56 & 106.85 & & \\
938 & 20.87 & 1253 & 105.10 & & \\
1515 & 27.37 & 162 & 115.51 & & \\
1299 & 29.74 & 1257 & 97.76 & & \\
2349 & 32.20 & 72 & 104.40 & & \\
\hline$\overline{K V}=26.78 \mathrm{~J} \pm 4.44 \mathrm{~J}$ & $\overline{K V}=103.73 \mathrm{~J} \pm 6.01 \mathrm{~J}$ & $\overline{K V}=244.01 \mathrm{~J} \pm 10.22 \mathrm{~J}$ \\
\hline
\end{tabular}

Table 3 - Charpy test results obtained with worn anvils, including average values $(\overline{K V})$ and standard deviations.

\begin{tabular}{|c|c|c|c|c|c|}
\hline \multicolumn{2}{|c|}{ Low energy (LL-157) } & \multicolumn{2}{|c|}{ High energy (HH-170) } & \multicolumn{2}{|c|}{ Super-high energy (SH-56) } \\
\hline Specimen ID & $\mathrm{KV}(\mathrm{J})$ & Specimen ID & $\mathrm{KV}(\mathrm{J})$ & Specimen ID & $\mathrm{KV}(\mathrm{J})$ \\
\hline 666 & 35.55 & 454 & 119.87 & 1059 & 258.50 \\
\hline 1711 & 34.99 & 995 & 120.13 & 418 & 246.90 \\
\hline 367 & 35.87 & 270 & 132.96 & 355 & 270.55 \\
\hline 1187 & 35.15 & 1026 & 118.80 & 11 & 263.49 \\
\hline 2019 & 32.76 & 498 & 121.02 & 305 & 257.43 \\
\hline 402 & 31.25 & 770 & 118.89 & 313 & 251.67 \\
\hline 2807 & 27.61 & 924 & 115.78 & 999 & 261.24 \\
\hline 1672 & 24.86 & 956 & 111.08 & 986 & 239.33 \\
\hline 1769 & 23.76 & 1128 & 108.97 & 910 & 261.53 \\
\hline 637 & 21.26 & 660 & 116.31 & 882 & 266.14 \\
\hline 1100 & 22.19 & 112 & 124.42 & & \\
\hline 1623 & 26.98 & 456 & 122.90 & & \\
\hline 2317 & 30.14 & 844 & 124.78 & & \\
\hline 178 & 34.35 & 1239 & 107.12 & & \\
\hline 959 & 33.79 & 1052 & 114.18 & & \\
\hline 1962 & 34.99 & 1255 & 121.02 & & \\
\hline 2342 & 35.39 & 668 & 120.58 & & \\
\hline 989 & 34.99 & 391 & 125.76 & & \\
\hline 1329 & 34.11 & 692 & 119.95 & & \\
\hline 2389 & 32.36 & 319 & 120.85 & & \\
\hline 1905 & 31.81 & 1238 & 109.14 & & \\
\hline 1104 & 28.08 & 892 & 110.38 & & \\
\hline 659 & 27.45 & 1137 & 114.53 & & \\
\hline 24 & 24.86 & 672 & 125.32 & & \\
\hline 2547 & 26.19 & 1233 & 125.05 & & \\
\hline \multicolumn{2}{|c|}{$\overline{K V}=30.43 \mathrm{~J} \pm 4.69 \mathrm{~J}$} & \multicolumn{2}{|c|}{$\overline{K V}=118.79 \mathrm{~J} \pm 6.28 \mathrm{~J}$} & \multicolumn{2}{|c|}{$\overline{K V}=257.68 \mathrm{~J} \pm 9.36 \mathrm{~J}$} \\
\hline
\end{tabular}

All specimens at the low- and high-energy level fractured completely during the test, while all the super-high-energy specimens exited the machine unbroken.

All specimens tested came from failed verification lots (i.e., not satisfying the NIST certification requirements), as no certified reference specimens were available at the time of testing. 


\section{Statistical analyses}

In order to compare the results from new and worn anvils, we first assessed whether the variances of the $K V$ values were affected by anvil condition. To accomplish this, a twotailed $F$-test was conducted $[4,5]$ to test against the alternative that the variances were not equal at a 0.05 significance level $(\alpha)$. The results are summarized in Table 4 .

Table 4 - Summary of two-tailed $F$-tests on the equality of variances $(\alpha=0.05)$.

\begin{tabular}{|c|c|c|c|c|c|c|}
\hline Energy level & \multicolumn{2}{|c|}{ Low (LL-157) } & \multicolumn{2}{|c|}{ High (HH-170) } & \multicolumn{2}{|c|}{ Super-high (SH-56) } \\
\hline Anvil condition & New & Worn & New & Worn & New & Worn \\
\hline Mean $(\mathrm{J})$ & 26.78 & 30.43 & 103.73 & 118.79 & 244.01 & 257.68 \\
\hline Variance $\left(\mathrm{J}^{2}\right)$ & 19.71 & 21.99 & 36.16 & 39.50 & 104.41 & 87.58 \\
\hline$N$ & 25 & 25 & 25 & 25 & 10 & 10 \\
\hline$\overline{d f}$ & 24 & 24 & 24 & 24 & 9 & 9 \\
\hline$F$ & \multicolumn{2}{|c|}{1.1160} & \multicolumn{2}{|c|}{1.0923} & \multicolumn{2}{|c|}{1.1921} \\
\hline$F_{\text {critical }}$ & \multicolumn{2}{|c|}{1.9838} & \multicolumn{2}{|c|}{1.9838} & \multicolumn{2}{|c|}{3.1789} \\
\hline$p$ & \multicolumn{2}{|c|}{0.3951} & \multicolumn{2}{|c|}{0.4153} & \multicolumn{2}{|c|}{0.3989} \\
\hline
\end{tabular}

LEGEND $N=$ number of test results; $d f=N-1=$ degrees of freedom; $p=$ probability value, providing evidence against the null hypothesis (i.e., variances are different), to be compared with the significance level (0.05).

At all energy levels, the calculated $F$ values (ratio between the variances) are lower than the critical values $\left(F_{\text {critical }}\right)$ : therefore, there is not enough evidence to reject the null hypothesis that the two anvil conditions have different variance. In other words, we found that anvil condition has a negligible influence on the variability/scatter of Charpy results.

Next, we used the two-sample $t$-test (assuming equal variances) [4,5] to assess whether the influence of anvil condition on $K V$ values was statistically significant. Here, the null hypothesis is that the means of the two populations are equal with a significance level $\alpha=0.05$. The results for the three energy levels are provided in Table 5.

Table 5 - Summary of two-tailed $t$-tests on the equality of means $(\alpha=0.05)$.

\begin{tabular}{|c|c|c|c|c|c|c|}
\hline Energy level & \multicolumn{2}{|c|}{ Low (LL-157) } & \multicolumn{2}{|c|}{ High (HH-170) } & \multicolumn{2}{|c|}{ Super-high (SH-56) } \\
\hline Anvil condition & New & Worn & New & Worn & New & Worn \\
\hline Mean $(\mathrm{J})$ & 26.78 & 30.43 & 103.73 & 118.79 & 244.01 & 257.68 \\
\hline Variance $\left(\mathrm{J}^{2}\right)$ & 19.71 & 21.99 & 36.16 & 39.50 & 104.41 & 87.58 \\
\hline Pooled variance $\left(\mathrm{J}^{2}\right)$ & \multicolumn{2}{|c|}{20.85} & \multicolumn{2}{|c|}{37.83} & \multicolumn{2}{|c|}{96.00} \\
\hline$N$ & 25 & 25 & 25 & 25 & 10 & 10 \\
\hline$d f$ & \multicolumn{2}{|c|}{48} & \multicolumn{2}{|c|}{48} & \multicolumn{2}{|c|}{1} \\
\hline$t$ & \multicolumn{2}{|c|}{2.8252} & \multicolumn{2}{|c|}{8.6595} & \multicolumn{2}{|c|}{3.1198} \\
\hline$t_{\text {critical,two-tail }}$ & \multicolumn{2}{|c|}{2.0106} & \multicolumn{2}{|c|}{2.0106} & \multicolumn{2}{|c|}{2.1009} \\
\hline$p_{\text {two-tail }}$ & \multicolumn{2}{|c|}{0.0069} & \multicolumn{2}{|c|}{$2.26 \times 10^{-11}$} & \multicolumn{2}{|c|}{0.0059} \\
\hline
\end{tabular}

As in the case of the $F$-test, the results are unequivocal at all energy levels: the influence of anvil condition on Charpy absorbed energy is statistically significant, with worn anvils providing consistently higher values. 


\section{Conclusions}

Our test results at different energy levels showed that worn anvils (outside ASTM tolerances but well within ISO tolerances, in terms of both corner radii and distance) tend to increase absorbed energy in a statistically significant manner.

These results do not support the proposal to relax the ASTM E23 upper tolerances on anvil radius and span to match the ISO $148-2$ values $(1.50 \mathrm{~mm}$ and $10.20 \mathrm{~mm}$, respectively). On the contrary, should test results from other laboratories confirm our conclusions, it would be appropriate to propose a revision of ISO 148-2 aimed at tightening these upper tolerances.

\section{References}

[1] ASTM E23-18, Standard Test Methods for Notched Bar Impact Testing of Metallic Materials, ASTM International, West Conshohocken, PA.

[2] ISO 148-1:2016, Metallic materials - Charpy pendulum impact test — Part 1: Test methods, International Standardization Organization, Geneva, Switzerland.

[3] ISO 148-2:2016, Metallic materials - Charpy pendulum impact test - Part 2: Verification of testing machines, International Standardization Organization, Geneva, Switzerland.

[4] Snedecor, G. W. and Cochran, W. G. (1989), Statistical Methods, Eighth Edition, Iowa State University Press.

[5] NIST/SEMATECH e-Handbook of Statistical Methods, http://www.itl.nist.gov/div898/handbook/, update April 2012. 


\section{ANNEX 1 \\ Presentation by A. Ishikawa \\ Japan Iron and Steel Federation \\ $(5 / 14 / 2019)$}




\title{
Tolerance of anvil radius in Charpy impact test machines
}

\author{
2019 May 14 \\ The Japan Iron and Steel Federation
}

\section{Proposal of revision (anvil tolerance)}

ASTM E23 ; +0.05 mm/-0.05 mm

[ISO $148-2 ;+0.5$

[ISO $148-2 ;+0.5 \mathrm{~mm} /-0 \mathrm{~mm}$ ]

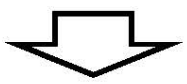

Proposal of revision (SB)

\begin{tabular}{|c|c|c|}
\hline & Radius & Distance \\
\hline Initial & $+0.05 \mathrm{~mm} /-0.05 \mathrm{~mm}$ & $+0.05 \mathrm{~mm} /-0.05 \mathrm{~mm}$ \\
\hline After use & $+0.50 \mathrm{~mm} /-0.05 \mathrm{~mm}$ & $+0.20 \mathrm{~mm} /-0.05 \mathrm{~mm}$ \\
\hline
\end{tabular}




\section{Result of voting [E28.07(18-02)]}

Affirmative ; 36

Negative $; 4+2^{*}$ ( 2 technical $\& 4$ editorial)

$\left[{ }^{*}\right.$; non-official voting member]

Technical 1)Needs more lab data

2)Worry unknown effects

Editorial 1)Unclear \& confusing

2)Separate initial condition and used condition

3)Add figure of used condition

\section{Actual data (provided by 3 labs)}
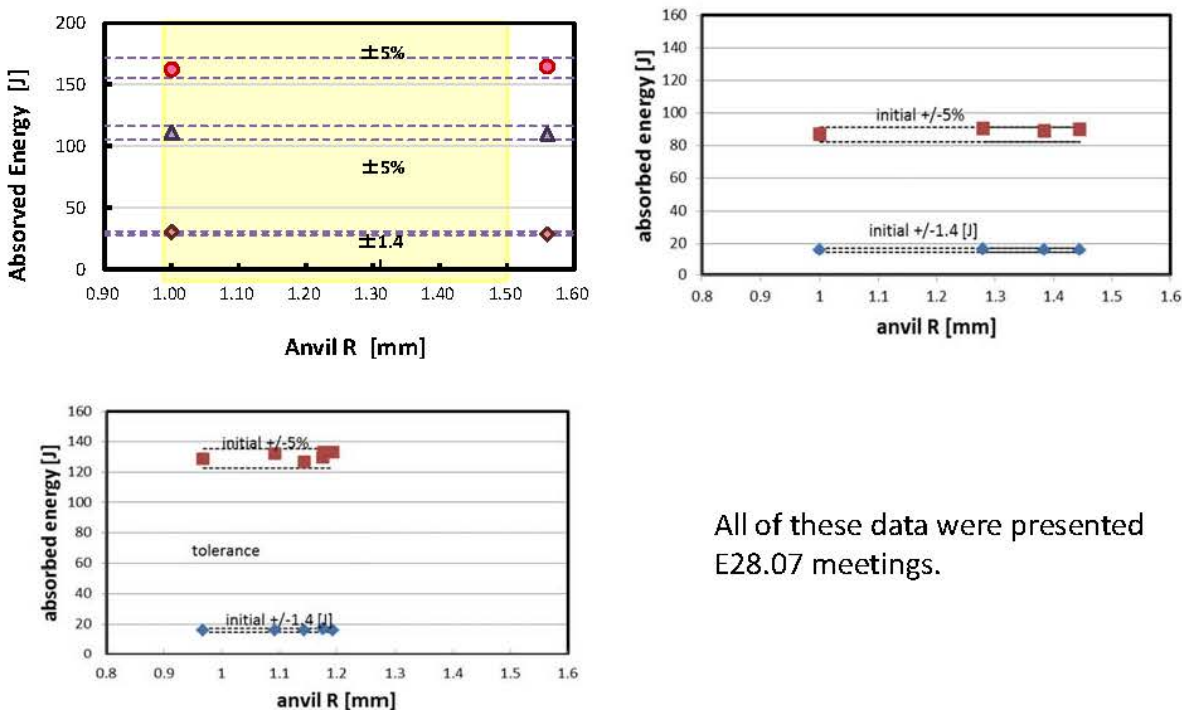

All of these data were presented E28.07 meetings. 


\section{Surround of ISO based standard}

- Tolerance of anvil radius of ISO based standards

$;+0.5 \mathrm{~mm} /-0 \mathrm{~mm}$

(ISO based standards are widely used in European

countries and Japan)

- They don't have any problems for about 30 years.

\section{Suggestion from negative voter}

- The tolerance of anvil radius shall be $+0.5 \mathrm{~mm} /-0.05 \mathrm{~mm}$ between verification, but $+/-0.05 \mathrm{~mm}$ when indirect verification is performed. 


\section{Proposed re-ballot}

- Initial condition and naturally worn (used) condition will be specified separately.

- Add;

-Figure of naturally worn (used) condition

-"The tolerance of anvil radius shall be $+0.5 \mathrm{~mm} /-0.05 \mathrm{~mm}$ between verification, but $+/-0.05 \mathrm{~mm}$ when indirect verification is performed."

\section{Initial Condition of Charpy Anvils and Supports}

Initial (new) condition of Charpy anvils and supports shall conform to the dimensions and tolerances shown in Fig. A1.2. Other dimensions of the pendulum and supports should be such as to minimize interference between the pendulum and broken specimens.

\begin{tabular}{cccc}
\hline ID Num & Designation & Dimension & Tolerance \\
\hline 1 & Span between anvils & $40.00 \mathrm{~mm}$ & $\pm 0.05 \mathrm{~mm}$ \\
2 & Anvil radius & $1.00 \mathrm{~mm}$ & $\pm 0.05 \mathrm{~mm}$ \\
3 & Anvil angle & $80^{\circ}$ & $\pm 2^{\circ}$ \\
4 & Anvil-Support angle & $90^{\circ}$ & $\pm 0.15^{\circ}$ \\
A \& B & Surface finish, Anvils & $0.1 \mu \mathrm{m}(\mathrm{Ra})$ & $\leq$ \\
\hline
\end{tabular}




\section{FIG. A1.2}
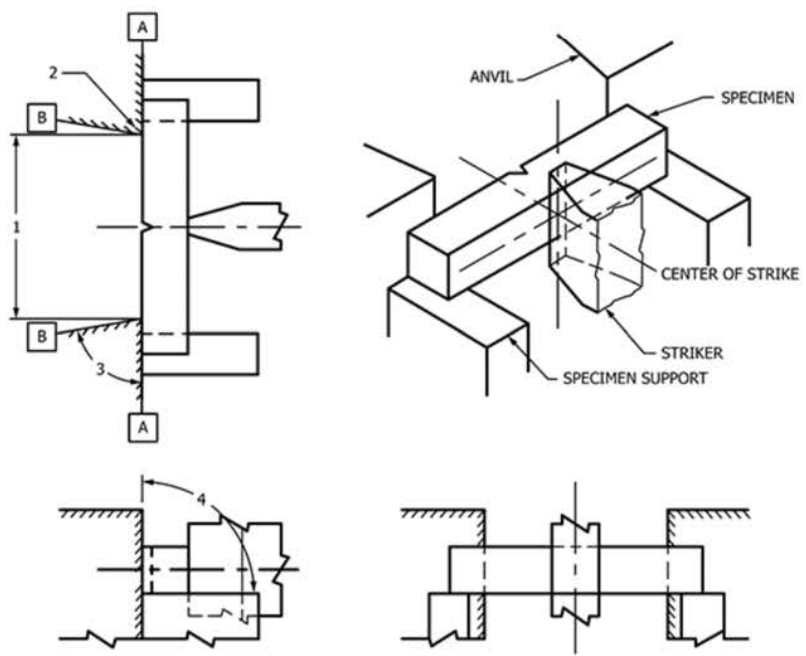

\section{Naturally Worn (used) Condition of Charpy Anvils}

Naturally worn (used) condition of Charpy the profile shall remain contained between the initial profile and an arc with radius $\mathrm{Rf}=1.50 \mathrm{~mm}$, as shown in Fig. A1.3. With the naturally worn (used) condition), the allowable tolerance for the span between anvils shall become ${ }_{-0.05}^{+0.20} \mathrm{~mm}$.

NOTE The arc with radius $\mathrm{Rf}=1.50 \mathrm{~mm}$ has the intersection on the tangent point with the maximum initial radius of $\mathrm{Ri}=1.05 \mathrm{~mm}$ on Surface $A$, and the tangent point on Surface B.

\begin{tabular}{cccc}
\hline ID Num & Designation & Dimension & Tolerance \\
\hline 1 & Span between anvils & $40.00 \mathrm{~mm}$ & $+0.20 \mathrm{~mm} /-0.05 \mathrm{~mm}$ \\
2 & Anvil radius & $1.00 \mathrm{~mm}$ & $+0.50 \mathrm{~mm} /-0.05 \mathrm{~mm}$ \\
3 & Anvil angle & $80^{\circ}$ & $\pm 2^{\circ}$ \\
\hline
\end{tabular}

The tolerance of anvil radius shall be $+0.5 \mathrm{~mm} /-0.05 \mathrm{~mm}$ between verification, but $+/-0.05 \mathrm{~mm}$ when indirect verification is performed. 


\section{FIG. A1.3}

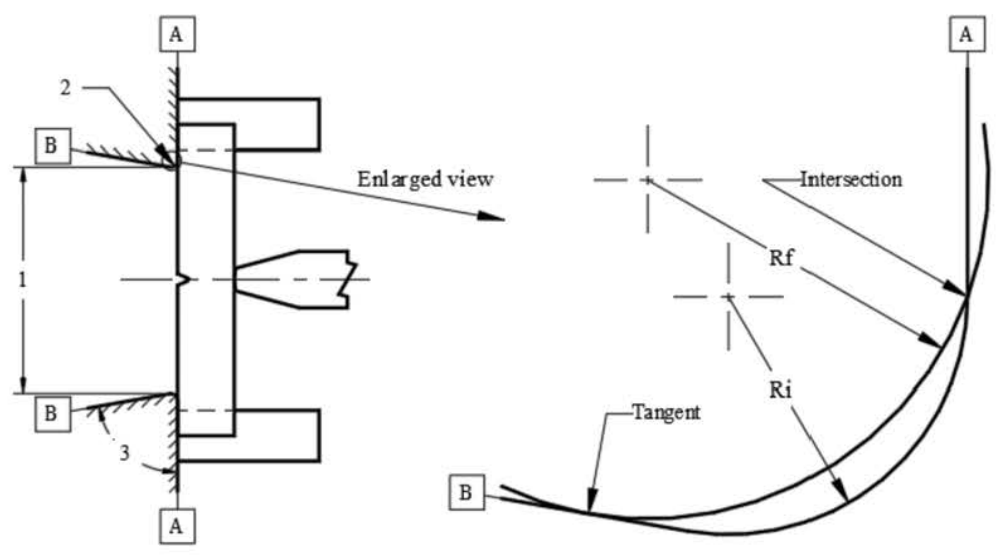

Thank you for your attention. 
ANNEX 2

\section{Data Collection Protocol}




\section{Data collection/Inter-laboratory exercise for the revision of anvil radius tolerance in Charpy impact testing (ISO 148-1)}

\section{Introduction}

When the revision of the anvil radius tolerance for Charpy testing in the ASTM E23 standard was balloted at E28.07 sub-committee, a negative voter pointed out that more actual test data should be collected and assessed. The E28.07 sub-committee decided to set up a Task Force to respond to this negative.

This is my proposal for collecting the required test data.

\section{Data collection}

\subsection{Timing for testing test pieces}

1) Just before the periodic verification (absorbed energy data using worn anvil)

\subsection{Test pieces}

1) Standard test pieces which have verified value of absorbed energy

\subsection{Absorbed energy}

1) Measure absorbed energy of test pieces (3-5 specimens/set), with the timing specified in 2.1 .

2) Calculate average value of the set.

3) Calculate relative error with respect to the certified value of the specimens. Relative error

$$
=\frac{(\text { Absorbed energy using worn anvil })-(\text { Certified value of absorbed energy })}{\text { (Certified value of absorbed energy })}
$$

\subsection{Anvil profile}

1) Mold the profile of the worn (end-of-life) anvils, obtaining replicas.

2) Measure the anvil radius in accordance with the attached procedure.

\subsection{Distance between anvils}

1) Measure the distance between anvils (anvil span) just before the periodic verification.

\section{Report}

1) Certified absorbed energy (if available)

2) Absorbed energy using worn anvils (mean value)

3) Absorbed energy using new anvils (mean value)

4) Photographs of worn anvil radius and its replicas

5) Distance between anvils (anvil span) just before periodic verification 
$<$ Attached Procedure $>$

How to determine worn anvil radius

1) Mold (obtain replicas) of the worn anvils.

2) Slice the replicas in the middle of the worn areas.

3) Take a photo of the replica profiles.

4) Determine the inscribed circle which is tangent to the profile in 3 tangent points (see figure);

- Surface A

- Maximum worn point

- Surface B

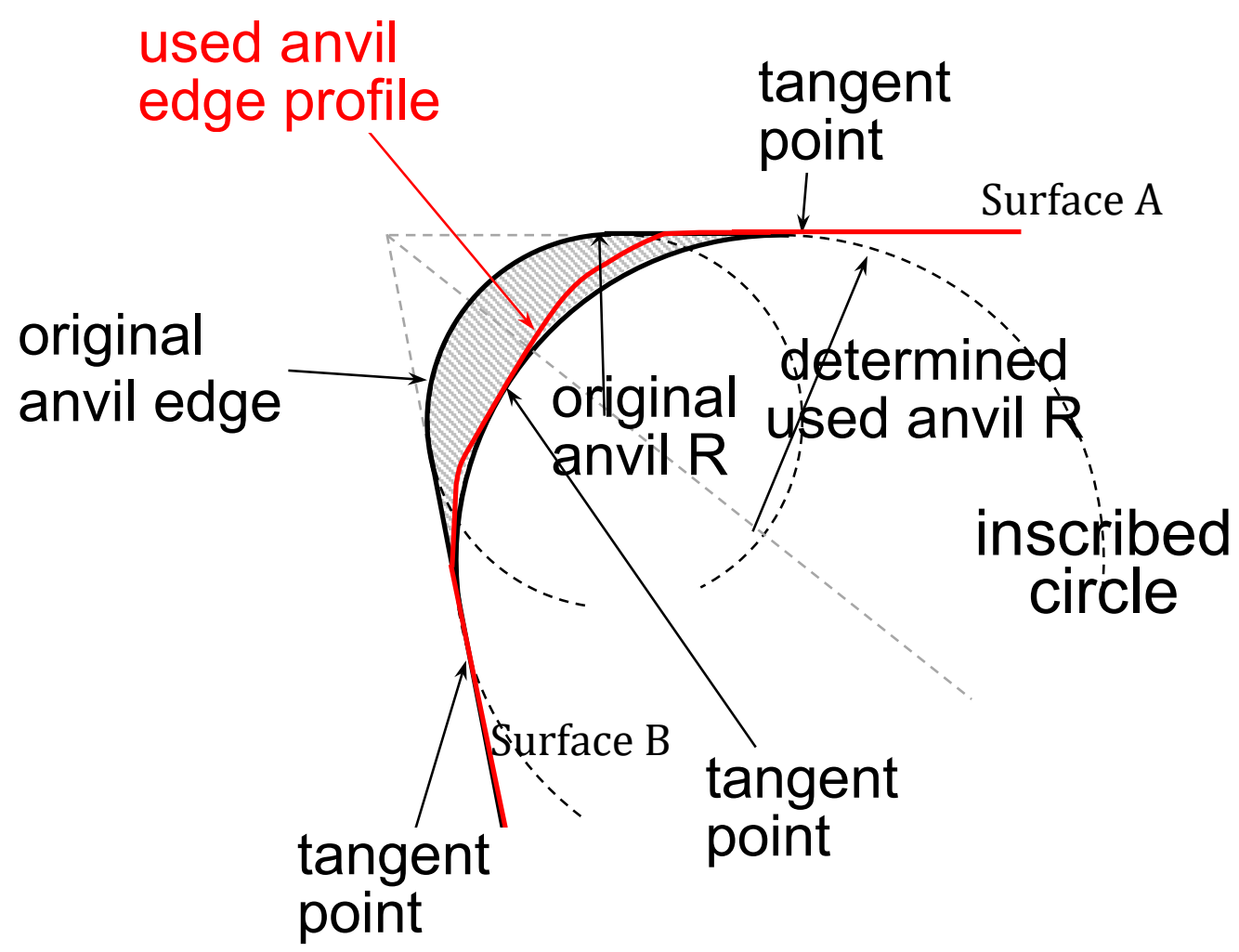




\section{ANNEX 3 \\ Pictures of anvil replicas with inscribed circles}




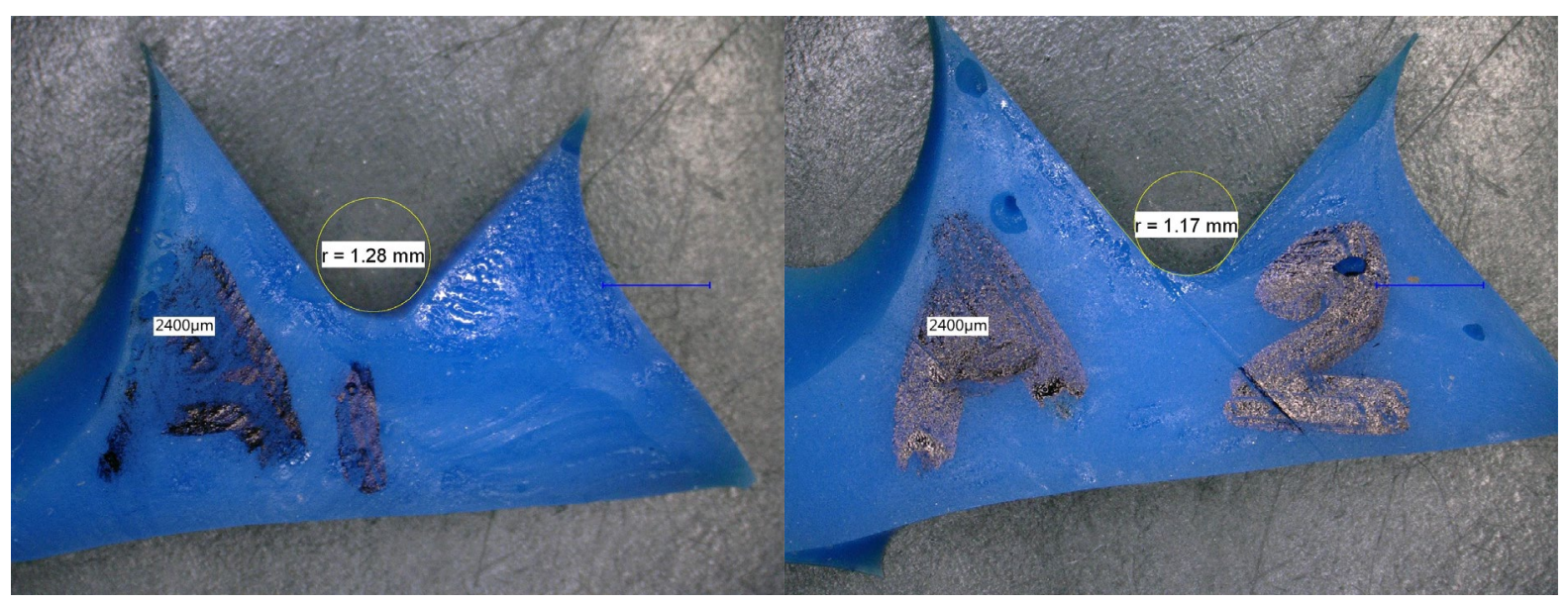

Anvil A - Positions P1 (left) and P2 (right)

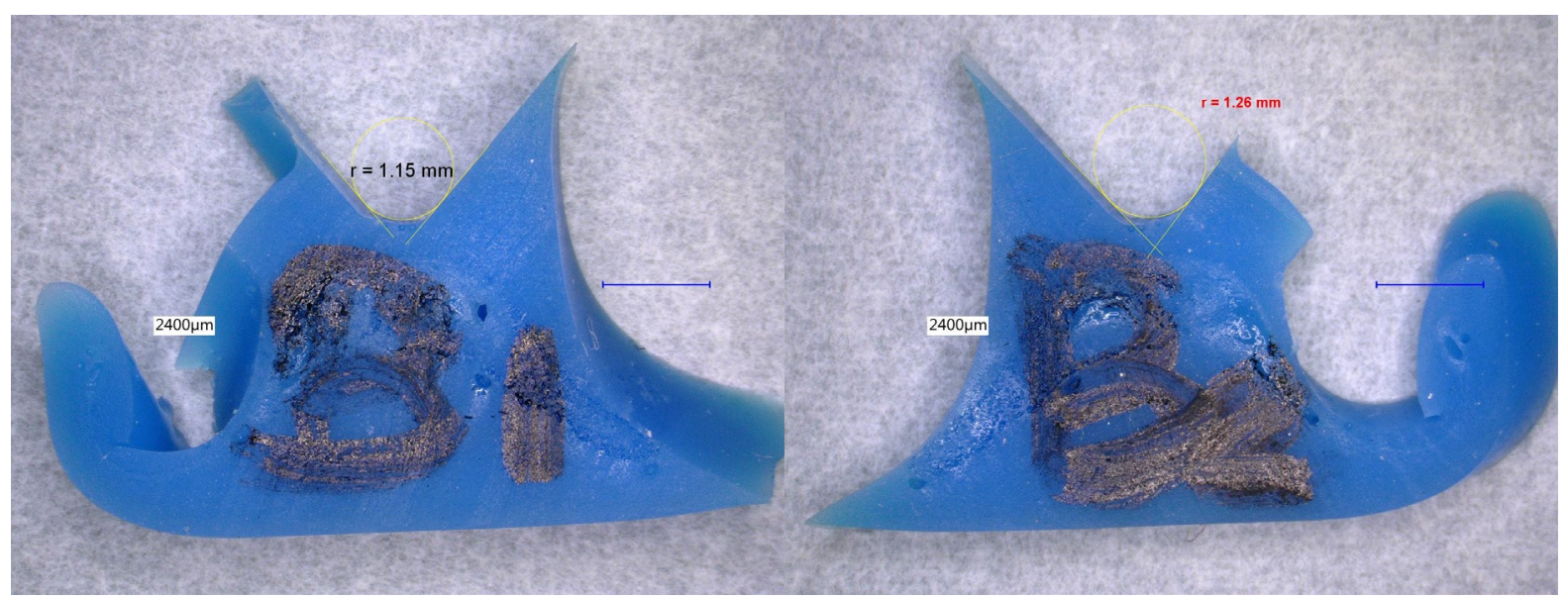

Anvil B - Positions P1 (left) and P2 (right)

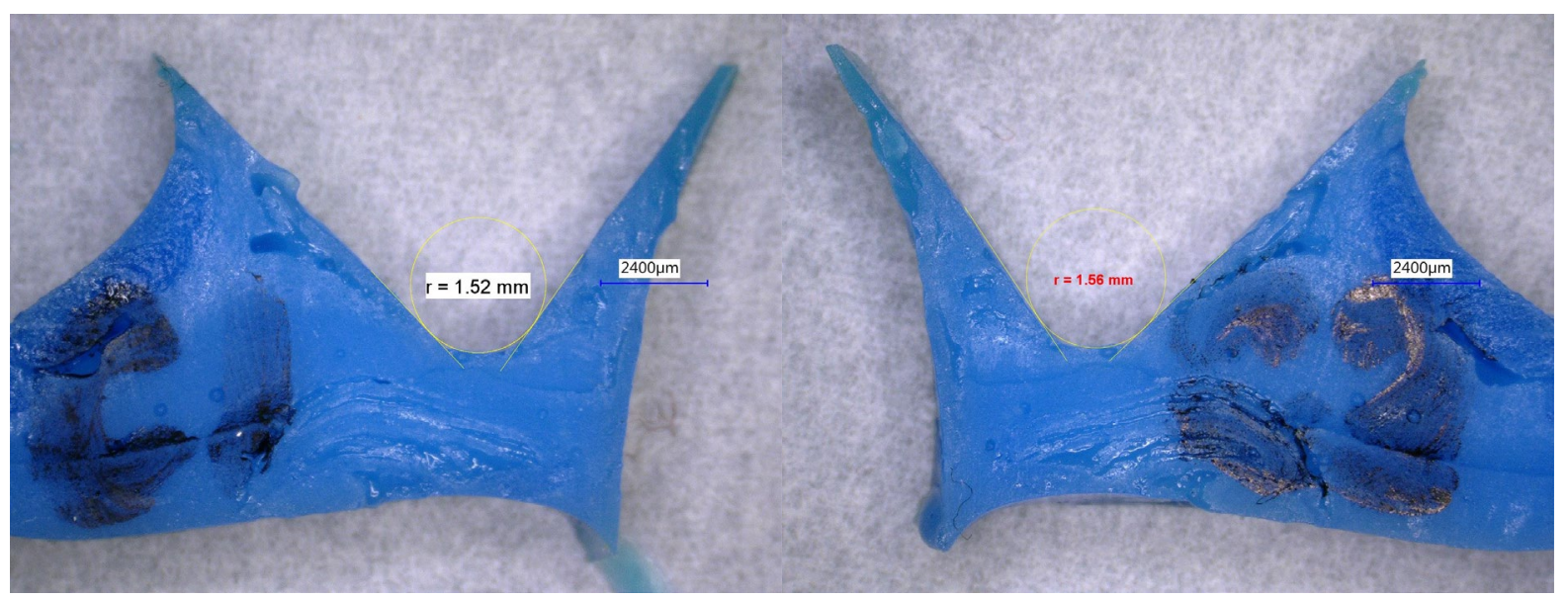

Anvil C - Positions P1 (left) and P2 (right) 


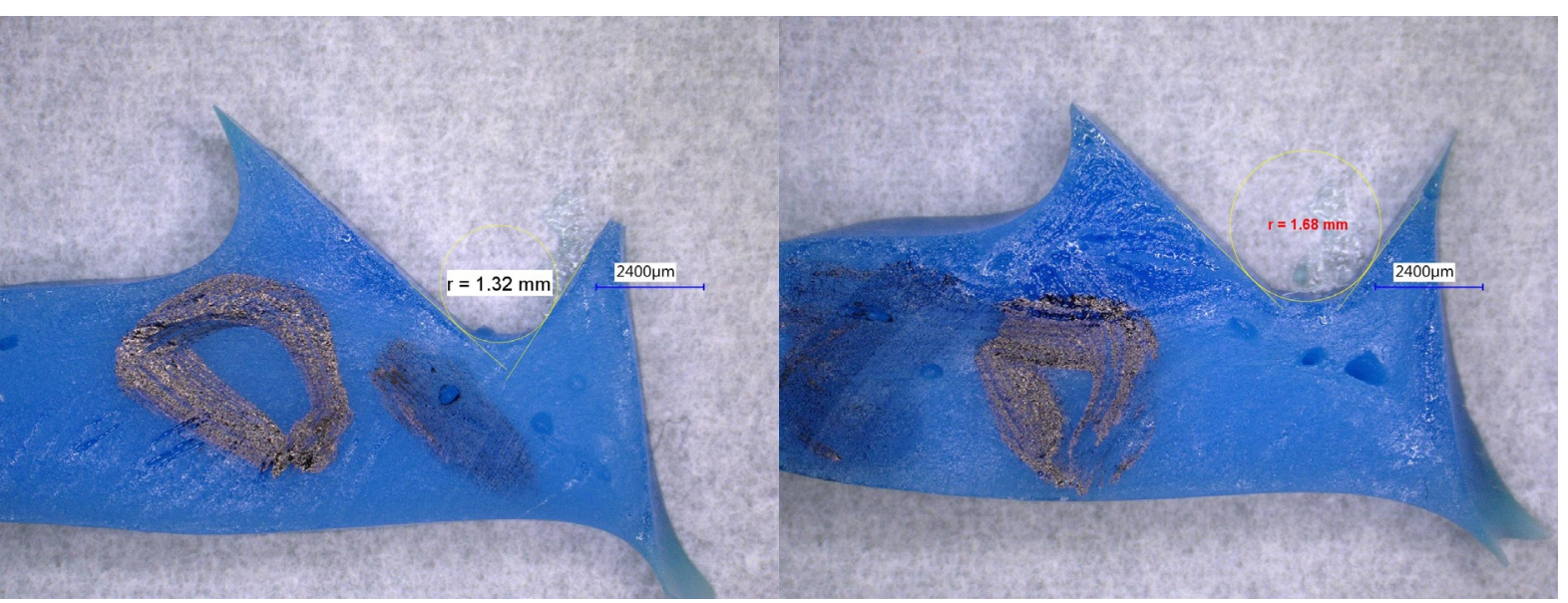

Anvil D - Positions P1 (left) and P2 (right)

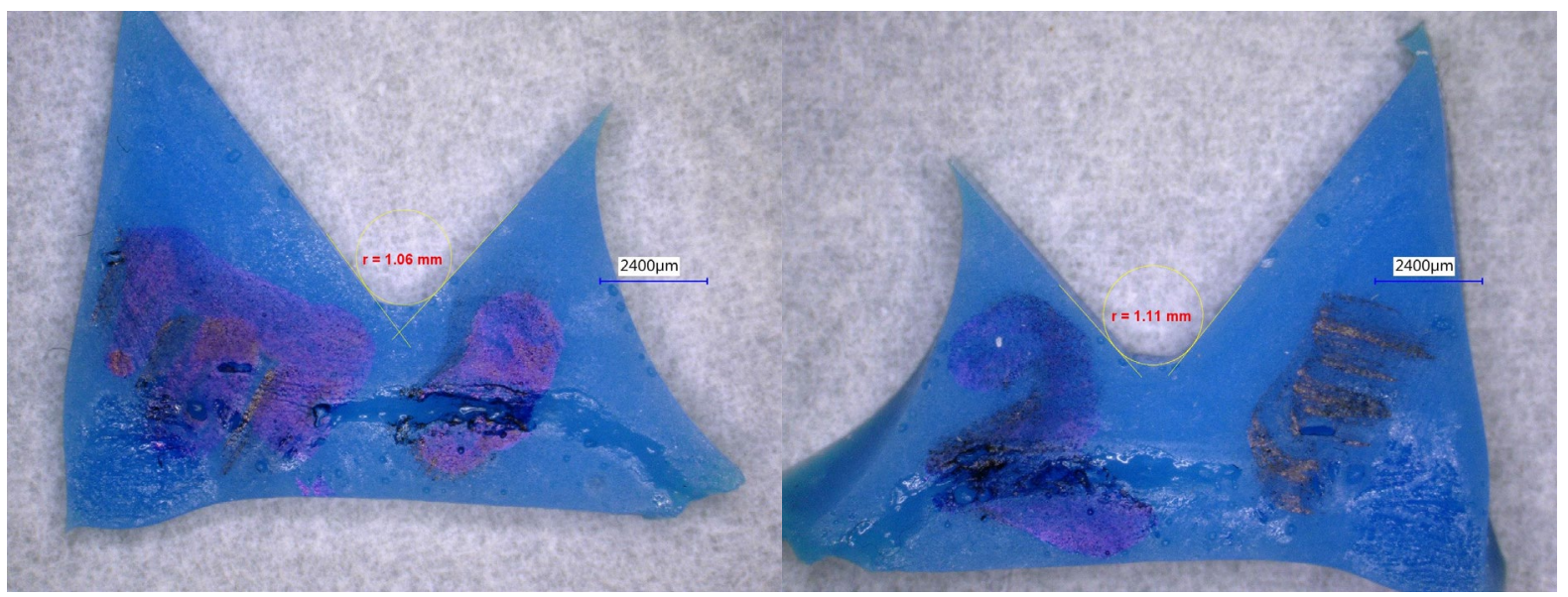

Anvil E - Positions P1 (left) and P2 (right)

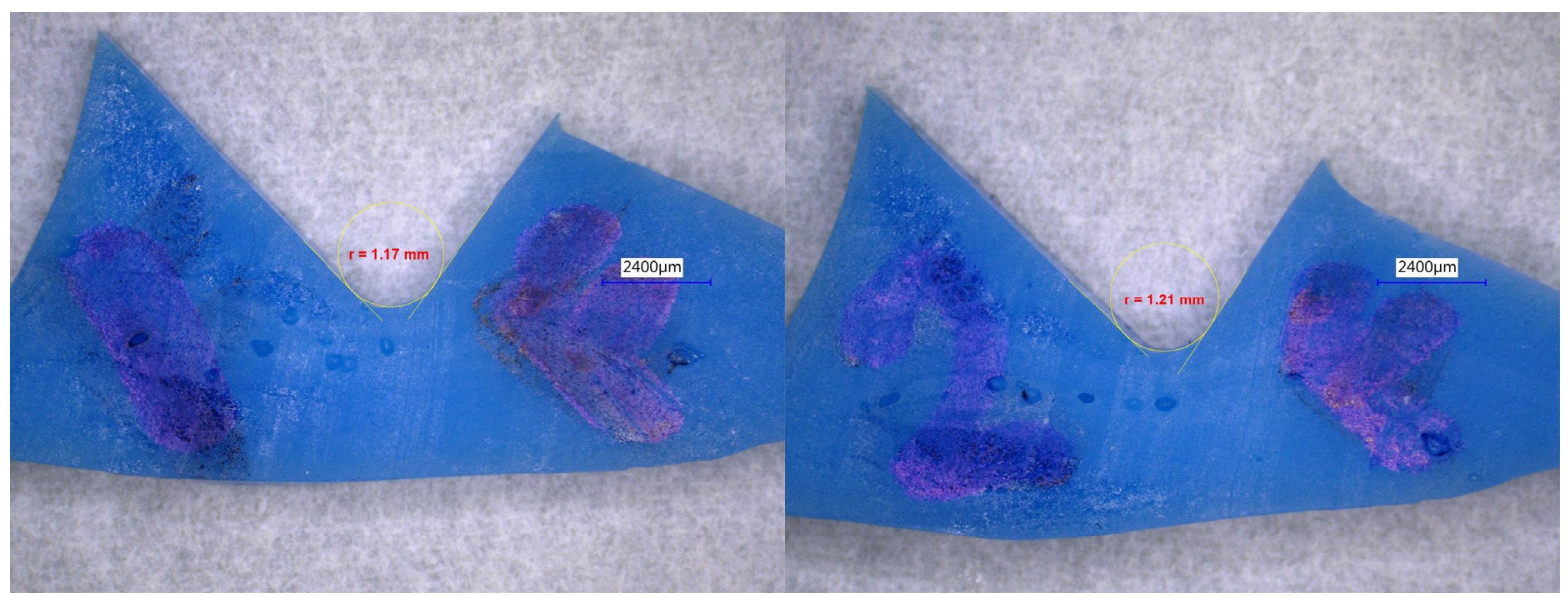

Anvil F - Positions P1 (left) and P2 (right) 


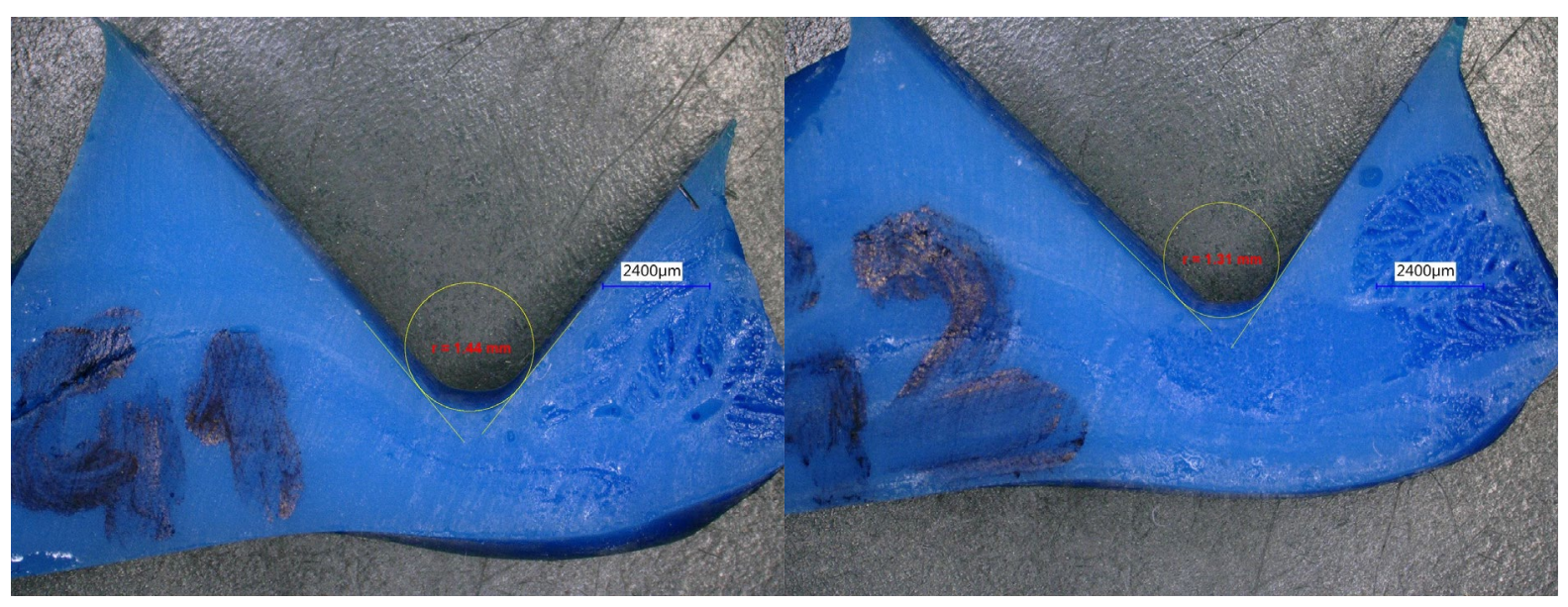

Anvil G - Positions P1 (left) and P2 (right)

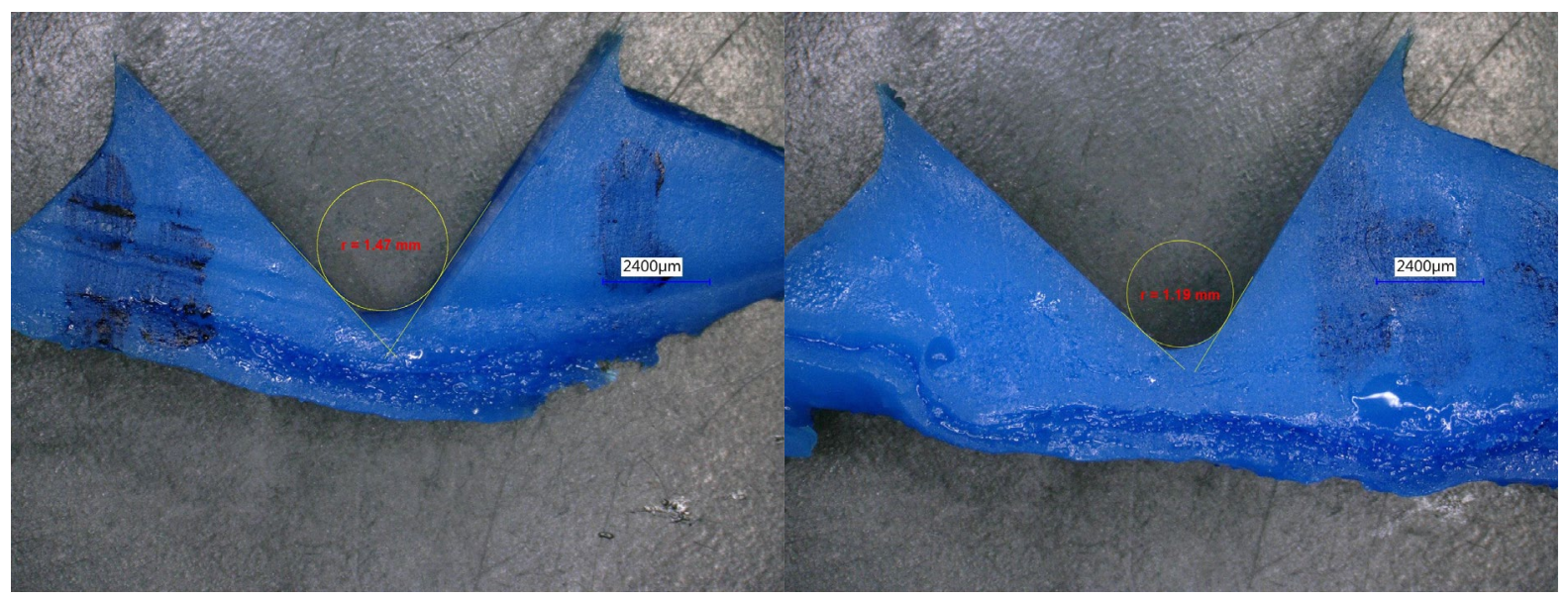

Anvil H - Positions P1 (left) and P2 (right) 